\title{
An Examination of Talent Management Concepts in Knowledge Intensive Settings
}

\author{
Eoin Whelan ${ }^{1}$, David Collings ${ }^{2}$, and Brian Donnellan ${ }^{3}$ \\ ${ }^{1}$ Dept. of Management and Marketing, Kemmy Business School, \\ University of Limerick, Ireland \\ eoin.whelan@ul.ie \\ ${ }^{2}$ J.E Cairnes School of Business and Economics, NUI Galway, Ireland \\ david.collings@nuigalway.ie \\ ${ }^{3}$ Brian Donnellan, Innovation Value Institute, NUI Maynooth, Ireland \\ brian.donnellan@nuim.ie
}

\begin{abstract}
Despite more than a decade of hype around the concept of talent management, we still have a relatively limited knowledge regarding its application in practice. In this paper we examine how the concepts of talent management apply in knowledge intensive settings. A case study of a high-technology R\&D group is conducted. Extending the technological gatekeeper theory, we apply social network analysis (SNA) techniques to identify those employees critical to the knowledge flow network. The specific talents exhibited by these individuals are then explored and we point to some organisational level interventions which can facilitate knowledge intensive organisations in fully exploiting their resources to maximise innovative capabilities.
\end{abstract}

Keywords: Talent management, technological gatekeeper, knowledge diffusion, social network analysis, R\&D.

\section{Introduction}

The global economic climate has altered significantly since a group of McKinsey consultants coined the phrase "The War for Talent" which brought the topic of talent management to the fore for practitioners and academics alike. While the economic context may have altered radically since the 1990s when the concept emerged, the underlying premise remains valid. It is a firm's human resources that provide a key source of sustainable competitive advantage $[1,2]$. However, as we know from the resource based theory, possessing resources is insufficient to create competitive advantage. Firms must be appropriately organised to fully exploit their resources to attain a competitive advantage [3]. Talent management plays a key role in assisting the organisation to ensure its human resources are utilised to the fullest extent. Talent management is regarded by many as one of the most critical HR challenges that organisations will face over the next decade [4]. Yet, despite a decade of debate on the importance of talent management, the concept itself remains somewhat under-developed and underexplored. In spite of the rhetoric of strategic integrated talent management systems in 
the practitioner literature, paradoxically the evidence suggests that relatively few organisations manage talent on a coordinated or effective basis [5, 6].

In light of the above challenges, the purpose of this paper is to advance our understanding of talent management by identifying and examining talented individuals in the context of Research \& Development (R\&D). We specifically choose this setting given the strategic importance of R\&D in driving an organisation's innovation capabilities [7]. In this effort, we revisit the highly influential technological gatekeeper theory and argue that the talented individuals who will contribute most to organisational success in R\&D settings are the small number of individuals who occupy pivotal positions in the knowledge flow network. Consequently we seek to answer two key questions: 1) Is the technological gatekeeper still a pivotal position in the modern R\&D group, and 2) What are the specific competencies required by those individuals who occupy pivotal positions in the R\&D knowledge flow network? Drawing on social network analysis (SNA) and interview evidence from a single case study, we find that the gatekeeper role is indeed pivotal. However, the role has evolved and undergone a division of labour. It is now rare for a single individual to possess all the talents necessary to effectively acquire and disseminate external knowledge.

\section{What Is Strategic Talent Management?}

Despite the widespread use of the terminology and its perceived importance, there is a degree of debate, and indeed confusion around the conceptual and intellectual boundaries of talent management. Broadly there are four key streams of thought on what talent management is [8]. Some authors merely substitute the label talent management for HR management. Studies in this tradition often limit their focus to particular HR practices such as recruitment, leadership development, succession planning and the like. A second strand of authors emphasises the development of talent pools focusing on "projecting employee/staffing needs and managing the progression of employees through positions" [8, p.140]. The third stream focuses on the management of talented people. Finally, there is an emerging body of literature which emphasises the identification of key positions which have the potential to differentially impact the competitive advantage of the firm [9, 10].

We adopt Collings et al (in press) definition: as activities and processes that involve the systematic identification of key positions which differentially contribute to the organisation's sustainable competitive advantage, the development of a talent pool of high potential and high performing incumbents to fill these roles, and the development of a differentiated human resource architecture to facilitate filling these positions with competent incumbents and to ensure their continued commitment to the organisation. They argue that the first step in any talent management system should be the identification of the pivotal talent positions which have the greatest potential to impact on the organisation's overall strategic intent. This perspective calls for a greater degree of differentiation of roles within organisations and an emphasis on strategic over nonstrategic jobs [9] or organisational roles which have the potential for only marginal impact vis-à-vis those which can provide above-average impact [10]. However, the extent to which a variation in performance between employees in strategic roles is also a significant consideration [11]. This contrasts with the status-quo in many firms where over-investment in non-strategic roles is commonplace [10,11]. 


\section{The Technological Gatekeeper: A Pivotal Position in R\&D?}

Throughout the 1970s and 1980s, a rich stream of research examined the processes through which knowledge of the latest technological advances enters the R\&D group. This particular stream was headed by MIT's Thomas Allen and his seminal book Managing the Flow of Technology [12] documents over a decade's worth of studies with some of the largest American R\&D corporations. Allen discovered that knowledge of the latest scientific and technological developments entered the R\&D group through a two-step process. Not every R\&D professional was directly connected with external sources of knowledge. Instead, a small minority had rather extensive external contacts and served as sources of knowledge for their colleagues. These individuals were termed 'technological gatekeepers' $[12,13,14]$ as they served as the conduit through which knowledge of external technology flows into the R\&D group. Essentially, a gatekeeper is an individual who acquires technological knowledge from the outside world (step 1) and disseminates this to his or her R\&D colleagues (step 2). A more formal definition explains that technological gatekeepers are those key individual technologists who are strongly connected to both internal colleagues and external sources of knowledge, and who possess the ability to translate between the two systems $[12,13,14]$.

Gatekeepers make a significant contribution to the innovation process by virtue of their pivotal position in the knowledge flow network. Not only do they act as the firm's antennae tuned to a variety of external broadcasting sources, they also exploit their familiarity of the internal knowledge network to internalise emerging technologies. Allen \& Cohen [13] noted when studying gatekeepers in the R\&D division of a large aerospace firm that "...if one were to sit down and attempt to design an optimal system for bringing in new technological information and disseminating it within the organisation, it would be difficult to produce a better one than that which exists." Indeed, subsequent studies have provided the empirical evidence to support this claim. Development focused R\&D projects containing gatekeepers have been found to be significantly higher performing than those without $[15,16]$.

While we argue that the gatekeeper theory provides a useful lens to examine talented individuals in $\mathrm{R} \& \mathrm{D}$, we acknowledge that the theory is a little outdated. It has been over 20 years since any significant investigation into the gatekeeper concept has been conducted. In the time since, there have been huge advances in information and communication technologies. The gatekeeper existed in a time when it was a difficult and time consuming process for the average $R \& D$ professional to acquire knowledge from beyond the company's boundaries. Thus, the gatekeeper mediated with the outside world on their behalf. What technologies such as the World Wide Web have changed is the ease and speed with which employees at all organisational levels can access and disseminate information. As a result, recent studies suggest that the modern gatekeeper may have morphed into another role providing an altogether different range of services [17]. While we have a good understanding of the role and characteristics of the traditional gatekeeper, scant attention has been paid to how the gatekeeping function is performed in the modern R\&D group. From the talent management perspective, this study seeks to explore whether the technological gatekeeper remains a pivotal position in the modern R\&D setting and further highlight how organisations can identify and define those performing the gatekeeping function in the modern 
R\&D group. Thus, our first research question asks: Is the technological gatekeeper still a pivotal position in the modern R\&D group?

Once the pivotal positions are identified, the strategic talent management system advocates the development of a talent pool of high potential and high performing incumbents to fill these roles. In order to groom potential incumbents, management needs to know the specific talents of those occupying key positions in the R\&D knowledge flow network. Thus, our second research question asks: What are the specific competencies required by those individuals who occupy pivotal positions in the R\&D knowledge flow network?

\section{The Case Study Site}

Utilising a case study approach, we studied the R\&D group of a medical device manufacturing firm operating in Ireland, MediA ${ }^{1}$. The R\&D group, referred to in the rest of the paper as Group A, consisted of 42 engineers who specialised in the designed and development of catheter-based minimally invasive devices.

\subsection{Identifying Pivotal R\&D Positions through Social Network Analysis}

Identifying pivotal positions is something organisations find difficult. We propose a novel approach in this regard. Given the well established centrality of knowledge flows in the R\&D innovation process, we use SNA techniques to identify pivotal talent positions. SNA or sociometry is an established social science approach of studying human relations and social structures by "disclosing the affinities, attractions and repulsions between people and objects" [18]. In simple terms, SNA is the mapping and measuring of relationships and flows between people, groups, organisations, computers or other information/knowledge processing entities [19].

The goal of this study is to demonstrate how SNA supports the identification of talented individuals in knowledge intensive settings. In our argument, these are the handful of individuals performing the gatekeeping role. We adopt the classic definition of a gatekeeper as an individual who is both an internal communication star (i.e. in the top $20 \%$ of internal communication measures) and an external communication star (i.e. in the top $20 \%$ of external communication measures). While it can be argued that this is an arbitrary measure, it serves our purpose of identifying the key individuals in the R\&D knowledge flow network.

Figure 1 presents the SNA of Group A. To collect these data, all group members were asked to complete a short online questionnaire on their internal and external communications. The SNA software package UCINET [20] was used to produce this diagram. The nodes in the diagram are the individual members of Group A and the lines represent the flow of technical knowledge between them. The more connected nodes tend to gravitate towards the centre of the network while those nodes with fewer connections are found on the periphery. Nodes $4,16,35$ and 40 did not complete the questionnaire hence the reason they are isolated on the left. Nodes 2, 11, 38 and 42 are also isolates because they have no reciprocated interactions with another group member. The external communication stars of the group are represented as

\footnotetext{
${ }^{1}$ Company names are fictitious to preserve anonymity.
} 
triangles. The size of the triangle is reflective of how well connected that individual is to external knowledge sources. For example, node 9 is the biggest triangle as this individual is the most frequent user of external knowledge sources.

Figure 1 reveals a number of key people in Group A's knowledge flow network. Firstly, there are nodes 7 and 37. Using the classic definition, only these two members (or 5\%) of Group A can be classified as technological gatekeepers. While external knowledge is imported and disseminated around the group by these two gatekeepers, the SNA evidence indicates that separate communication specialists also combine to perform the gatekeeping role. One set of boundary spanning individuals acquire external knowledge, and a largely different set of individuals distribute this knowledge around the group. The relationship between node 5 and node 25 can be used to demonstrate this process (the relationship between nodes 17 and 28 , nodes 9 and 6 , or nodes 15 and 6 could also have been used). Node 5 is an external communication star. This individual is well connected to external knowledge sources but is not very well connected internally. Node 5 acquires external knowledge and communicates this to node 25 . Node 25 , on the other hand, is well connected internally and can distribute this knowledge around the group through his or her many connections.

It must be noted however that the SNA evidence, and our interpretation of that evidence, only suggests that such a sequence of knowledge flow is evident. Semistructured interviews with selected group members were also conducted to validate this interpretation, and to explore the specific talents exhibited by these key individuals. Based upon the interview findings, table 1 summarises the specific competencies exhibited by those individuals occupying key positions in the knowledge flow network.

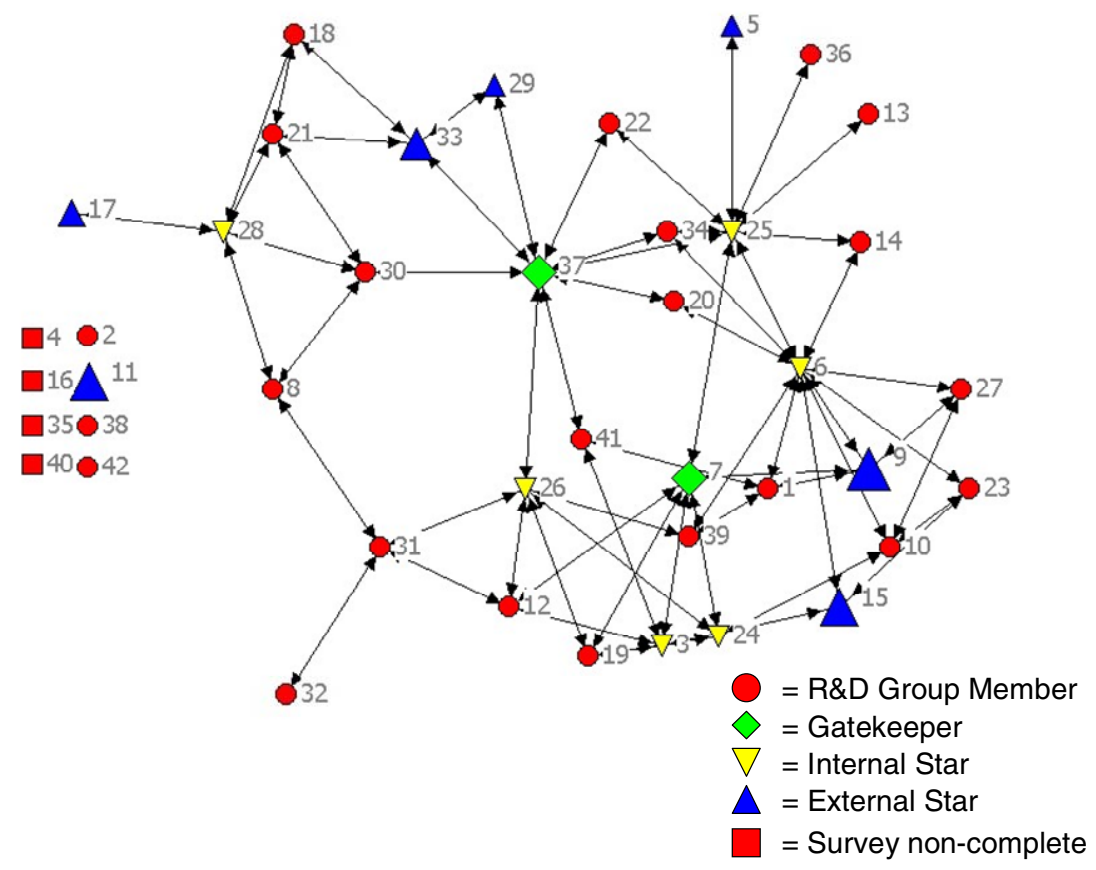

Fig. 1. A Social Network Analysis of Group A 
Table 1. Summary Table of those Performing the Gatekeeping Role

\begin{tabular}{|c|c|c|c|}
\hline & Key Skills & $\begin{array}{l}\text { Motivation/ } \\
\text { Attitudes }\end{array}$ & $\begin{array}{c}\text { Preferred } \\
\text { Media }\end{array}$ \\
\hline $\begin{array}{l}\text { External } \\
\text { Communication } \\
\text { Stars }\end{array}$ & $\begin{array}{l}\text { - Ability to acquire } \\
\text { relevant knowledge of } \\
\text { external developments } \\
\text { - Narrow and deep } \\
\text { technology domain } \\
\text { knowledge } \\
\text { - Strong analytical skills }\end{array}$ & $\begin{array}{l}\text { - Genuine interest in } \\
\text { keeping abreast of } \\
\text { emerging trends in } \\
\text { their specialty } \\
\text { - Primarily acquire } \\
\text { knowledge for own } \\
\text { use but lack the skills } \\
\text { to disseminate } \\
\text { effectively }\end{array}$ & $\begin{array}{l}\text { - Predominately } \\
\text { Web-based e.g. } \\
\text { Google search, } \\
\text { online } \\
\text { communities, } \\
\text { materials } \\
\text { websites }\end{array}$ \\
\hline $\begin{array}{l}\text { Internal } \\
\text { Communication } \\
\text { Stars }\end{array}$ & $\begin{array}{l}\text { - Ability to translate } \\
\text { complex external } \\
\text { knowledge into a form } \\
\text { understandable and } \\
\text { relevant to internal } \\
\text { colleagues } \\
\text { - Wider knowledge base } \\
\text { which facilitates } \\
\text { understanding the } \\
\text { context of new } \\
\text { knowledge and how it } \\
\text { fits with extant } \\
\text { knowledge }\end{array}$ & $\begin{array}{l}\text { - Enjoy helping others } \\
\text { - Develop their own } \\
\text { knowledge from } \\
\text { these interactions } \\
\text { - Expect reciprocation }\end{array}$ & - Email and oral \\
\hline Gatekeepers & $\begin{array}{l}\text { - Display both depth of } \\
\text { knowledge of external } \\
\text { communication star } \\
\text { and breadth of } \\
\text { knowledge of internal } \\
\text { communication star } \\
\text { - Highly sociable with } \\
\text { very good networking } \\
\text { skills enabling them to } \\
\text { develop extensive } \\
\text { internal and external } \\
\text { networks } \\
\end{array}$ & $\begin{array}{l}\text { - May acquire } \\
\text { knowledge for their } \\
\text { own use but also } \\
\text { transmit it others } \\
\text { - Enjoy helping others }\end{array}$ & $\begin{array}{l}\text { - External - both } \\
\text { Web-based and } \\
\text { oral } \\
\text { - Internal - Email } \\
\text { and oral }\end{array}$ \\
\hline
\end{tabular}

\section{Discussion and Conclusions}

This paper provides a very clear example of how pivotal positions can be identified in organisations. Recognising the importance of knowledge flows in the context of innovation in $\mathrm{R} \& \mathrm{D}$ settings, we argue that the technological gatekeeper role continues to represent a pivotal position. While we find that the gatekeeping tasks of acquiring and disseminating knowledge are integral to the $R \& D$ operation, we also find that these tasks no longer need to be performed by a single individual. Indeed, it is more likely that the gatekeeping role will be performed by external and internal communication specialists combining their unique talents together. Gatekeepers do exist, but they are rare. When Allen [12] first formulated the theory, the gatekeeping role could only be 
performed by a single individual because technical communications were predominately oral based. Among other skills, the traditional gatekeeper needed excellent social networking abilities in order to effectively acquire and disseminate knowledge orally. While other R\&D engineers may have wanted to perform the gatekeeping role, the lack of these social networking skills possibly impeded them. From the R\&D group we have studied, we find that Web technologies now enable the individuals that are interested in external developments to easily access that knowledge. Rather than having social networking skills, these external communication stars possess analytical and Internet search skills. However, the lack of excellent social networking skills inhibits the ability of the external stars to distribute that knowledge around the R\&D network themselves. This is the domain of a different set if individuals, the internal communication stars, who possess those excellent social networking abilities. A key contribution of the current paper is to identify the competencies evident in both internal and external communication stars (see table 2). This will provide organisations with the information required to identify these competencies in the individuals within their talent pools, to focus development interventions for the talent pool in developing these competencies and to facilitate the placing of internal and external communication stars in each R\&D group. Managers would also be interested to know what they can do to facilitate the external and internal communication star positions. While we would not advocate that management formally appoint individuals to these positions, we do advocate that the handful of key individuals who exhibit the competencies of the communication star be given the opportunity to display their talents. External stars could be freed any mundane administrative duties and allocated the time they need to scan the external environment for emerging technologies and trends. In terms of resources, all they need is a PC with an internet connection. However, it would more beneficial if external stars are given priority for external networking events such as conferences or tradeshows. Internal stars have a natural flair for getting to know others. If management fails to recognize the valuable role performed by these individuals, there is a danger that their knowledge dissemination efforts could be stifled. Internal stars need the opportunity to network. Involving these individuals in multiple projects throughout the firm will enable them to build their network more rapidly, allowing them to become more effective disseminators of knowledge.

Finally, our approach demonstrates the usefulness of SNA in identifying such positions. This is a concrete tool that can be utilized in practice to confirm the technological gatekeeper role as a pivotal position in R\&D settings. Additionally it is a tool that practitioners can use in the process of identifying high potential and high performing individuals for the organisation's talent pool.

\section{References}

1. Lowe, K.B., Milliman, J., De Cieri, H., Dowling, P.J.: International compensation practices: a ten-country comparative analysis. Human Resource Management 41(1), 45-66 (2002)

2. Caligiuri, P.M., Lazarova, M., Tarique, I.: Training, learning and development in multinational organizations. In: Scullion, H., Linehan, M. (eds.) International Human Resource Management: A critical text. Palgrave Macmillan, Hampshire (2005) 
3. Barney, J.: Gaining and sustaining competitive advantage. Addison-Wesley, Reading (1997)

4. Boston Consulting Group. The future of HR: Key challenges through 2015. Dusseldorf, Boston Consulting Group (2007)

5. Cappelli, P.: Talent management for the twenty-first century. Harvard Business Review, 74-81 (March 2008)

6. Cheese, P., Thomas, R.J., Tapscott, D.: The talent powered organization: Strategies for globalization, talent management and performance. London and Philadelphia: Keogan Page (2008)

7. Cohen, W., Levinthal, D.: Absorptive capacity: A new perspective on learning and innovation. Administration Science Quarterly 35, 128-152 (1990)

8. Lewis, R.E., Heckman, R.J.: Talent management: a critical review. Human Resource Management Review 16(2), 139-154 (2006)

9. Becker, B.E., Huselid, M.E., Beatty, R.W.: The differentiated workforce: Transforming talent into strategic impact. Harvard Business School Press, Boston (2009)

10. Boudreau, J.W., Ramstad, P.M.: Talentship, talent segmentation, and sustainability: A new HR decision science paradigm for a new strategy definition. Human Resource Management 42, 129-136 (2005)

11. Huselid, M.A., Beatty, R.W., Becker, B.E.: 'A players' or 'A positions'? The strategic logic of workforce management. Harvard Business Review, 110-117 (December 2005)

12. Allen, T.J.: Managing the flow of technology. MIT Press, Cambridge (1977)

13. Allen, T.J., Cohen, S.I.: Information flow in research and development laboratories. Administrative Science Quarterly 14(1), 12-19 (1969)

14. Allen, T.J., Tushman, M.L., Lee, D.M.S.: Technology transfer as a function of position in the spectrum from research through development to technical services. Academy of Management Journal 22(4), 694-708 (1979)

15. Tushman, M., Katz, R.: External communication and project performance: an investigation into the role of gatekeepers. Management Science 26(11), 1071-1085 (1980)

16. Katz, R., Tushman, M.: An investigation into the managerial roles and career paths of gatekeepers and project supervisors in a major R\&D facility. R\&D Management 11, 103$110(1981)$

17. Assimakopoulos, D., Yan, J.: Sources of knowledge acquisition for Chinese software engineers. R\&D Management 36(1), 97-106 (2006)

18. Moreno, J.L.: Sociometry in relation to other social sciences. Sociometry 1(1/2), 206-219 (1937)

19. Scott, J.: Social network analysis; a handbook. Sage Publications, London (2000)

20. Borgatti, S.P., Everett, M.G., Freeman, L.C.: Ucinet for Windows: Software for social network analysis. Analytic Technologies, Harvard (2002) 